\title{
Important Aspects of Investment Projects in Economic Relations in Digital Economic Processes
}

\author{
AbdulloSagdullaevichTurdiev ${ }^{1}$, NodirjonYakubdjanovichArtikov ${ }^{2}$, \\ GuliYarkinovnaMuxibova $^{3}$, ShavkatJabborberganovichKurbanbayev ${ }^{4}$ \\ ${ }^{1}$ Candidate of Economic Sciences, Associate Professor Department of "Economics and \\ Real Estate Management"Tashkent Institute of Architecture and Construction,Uzbekistan \\ ${ }^{2}$ Candidate of Economic Sciences, Associate Professor Department of "Economics and \\ Real Estate Management'Tashkent Institute of Architecture and Construction,Uzbekistan \\ ${ }^{3}$ Associate Professor,Department of "Economics and Real Estate Management" \\ Tashkent Institute of Architecture and Construction,Uzbekistan \\ ${ }^{4} 1$-course Master Department of "Economics and Real Estate Management" \\ Tashkent Institute of Architecture and Construction,Uzbekistan
}

\begin{abstract}
:
The article analyzes the concept of the digital economy, definitions of the digital economy, technological changes inherent in the digital economy, the impact of the digital economy on employment, the creation of a national system of digital economic security, the share of information and communication technologies in GDP, analysis of some indicators of the analysis of the number of special software tools used in this area.The article also analyzes the state and development of the digital economy in developed countries and, based on the results, discusses a number of issues and problems in the strategy of development of the digital economy in the Republic of Uzbekistan and its economic significance.Also, mechanisms for creating local platforms of digital technology in the country have been proposed.
\end{abstract}

Keywords: digital economy, development of digital economy, national digital economic security, software tools, economic indicators of the country.

Article Received: 16th October, 2020; Article Revised: 30th December, 2020; Article Accepted: 08th January, 2021

\section{Introduction}

Currently, the concept of the digital economy has appeared in economic theory and practice in a number of countries. A lot of work is being done in our country to develop the digital economy.First of all, it should be noted that the digital economy consists of a chain of interconnected production and management processes, an integral element of which is information that is carried out using digital technologies between chains (human, machine, cloud, data centers).It was characterized by the rapid development of digital technologies, the revolution in the field of information and the acceleration of the processes of globalization of the economy. The effectiveness of their use has been transformed into a growing knowledge, and socio-economic ties are expanding. The main factor of digital transformations in the activities of market participants is the development of digital culture.At the current stage of social and economic reform of society, the environment brings out the peculiarities of the institutional structure of society, and on this basis it is necessary to form new concepts and approaches.

\section{Analysis of the Relevant Literature}

When talking about the process of "digitization" of the economy and society (in English - digitization, that is, digitization, and sometimes digitalization), it is necessary to clarify the terminology. In the broadest sense, the process of "digitization" usually refers to the socioeconomic change that began with the initiative to widely adopt and assimilate digital technologies for creating, processing, exchanging and transmitting information [6]. 
A number of definitions are given to the concept of digital economy. In particular, Doctor of Economics, Corresponding Member of the Russian Academy of Sciences V.Ivanov described "Digital economy - a virtual environment that complements our reality." According to R. Meshcheryakov a professor at Tomsk State University, there are two approaches to the term "digital economy." The digital economy based on digital technologies and the digital economy that characterizes the exclusive domain of electronic goods and services: the first approach is called "classic" and the classic examples are telemedicine, distance learning, drug sales (movies, TVs, books, etc.).The second approach: "digital economy" is economic production using advanced digital technologies.

M.L. Kaluzhsky described the digital economy as an economic Internet activity, as well as forms, methods, tools and communication environment for its implementation. According to sources, the "digital economy" is a model of this type of economy, which to some extent works in practice.Digital economy is a production complex, a production system that creates products and services that provide life and convenience for man, where a certain cyber-physical (kiberfizicheskaya) system emerges. In our view, the digital economy is a virtual environment that creates products and services that provide convenience to people in a production complex, and is an economic production system using digital technologies. Also, the digital economy can encompass everything that can be formalized, i.e., it can be manifested in logical schemes.Life itself allows us to turn these "things" into a system of production, distribution, exchange and consumption. Indeed, before the virtual part of the world, located in the spiritual reality of man, was not an environment in which new ideas and products were created without the power of production.

\section{Research Methodology}

Economic statistics on the development of the digital economy in our country were analyzed. The activities of the digital economy have been closely studied and a database compiled. Based on the collected data, methods such as observation and comparison of economic analysis, systematic approach and logical approach were used effectively.

Implementation of the digital economy program in the Republic of Uzbekistan will allow toachieve the following [1]:

$>$ Complete elimination of legal barriers to the creation of new technologies through the creation of a new regulatory framework;

$>$ creation and development of infrastructure of digital economy, including development of networks, data processing centers, technical and software in accordance with modern requirements;

$>$ Ensuring comprehensive development and modernization of the education system;

$>$ To create a solid foundation for the development of various companies, firms, state-owned enterprises and businesses in the country;

$>$ The emergence of many organizations in the field of digital economy.

The Digital Economy Development Program should serve the following objectives [2]:

$>$ To create an ecosystem of the digital economy in the Republic of Uzbekistan;

$>$ to create institutions and infrastructure of the digital economy of the country;

> to take all necessary measures to create an information society covering all sectors of the republic;

$>$ To increase the competitiveness of our country on a global scale and in global markets.

Now, using the open data and literature available in the global information system, we will get acquainted with the main 
indicators of the formation of the infrastructure of the digital economy and its specific features on the example of several developed countries [3]:

The emergence of new types of services that was not possible before the advent of the Internet. From 1990 to the present, a number of new markets for products and services based on the use of the Internet and information technology have emerged.For example, messengers, aggregators, internet search engines, internet advertising, ecouching, e-learning and more. A clear example of the emergence of new types of services is e-commerce. In 2017, ecommerce accounted for $13.6 \%$ of retail sales in the UK, $13.1 \%$ in Germany, $4.2 \%$ in Russia and $9.6 \%$ in China.China's internet trade turnover in 2016 was around $\$ 400$ billion.

The development of society is creating new opportunities for the development and management of e-business. For example, cloud storage and management services are providing unprecedented opportunities for businesses.Firms and organizations no longer require office space, data centers, and there is no need to invest heavily in the creation of information systems.

The capitalization of e-business companies will depend on the number of users and the increase in their number [4]. This leads to a large amount of revenue from sales in companies. For example, YouTube receives 100 million requests a day, while Facebook has more than 2 billion users. The same factor can lead to a very large group of users, which not only increases the capitalization, but also generates a large amount of money in advertising. In 2015, for example, Facebook generated more than $\$ 26.9$ billion from advertising alone. In 2016, Facebook's annual revenue was \$ 27.6 billion and its net profit was $\$ 10.2$ billion. Thus, the digital economy is a new economic environment that creates new and enormous opportunities for business.

In the context of the digital economy, the structure and nature of competition will change completely. It is clear that under the influence of the digital economy and new technologies of e-commerce, business models will change completely. For example, aggregator companies in the passenger transport market (GettTaxi, Yandex.Taxi, etc.) have made many changes in the activities of transport companies and managed to bring them closer to consumers. Food delivery companies have also had great success in a competitive market, bringing vendors closer to consumers. As a result, traditional offline companies will be forced to transform their businesses or switch to online.This encourages entrepreneurs to set up their own businesses on the Internet. Nowadays, depending on the type of ecommerce channels, there are fully online companies such as AMAZON or OZON, social networks, messengers, eBay, AVITOs or retail networks, online stores and logistics companies that place their ecommerce channels in traditional off-line business.

- The digital economy has made it possible for businesses to search for new ideas based on rapid business analytics analysis and to provide feedback to customers. This allowed for a reactive impact on the innovative expectations of potential customers.As a result of such work GoogleAnalitics and Yandex. Free services such as metrics have emerged.

- The digital economy is also characterized by a significant reduction in the life cycle of innovations [5]. This will lead to the rapid emergence of many new models of smartphones, computers, mobile applications, new versions of computer games. According to scientists and experts, new innovative transport systems are expected to appear in transport as well. Examples include magnetic levitation vehicles, vacuum vehicles, hyperloop systems, and more. 
- Mass collaboration, sharing economy, production of products and services, crowdfunding [6]. The sharing economy has changed the attitude of many members of society towards the possession of material wealth. For example, many young people in developed countries are not very interested in buying and owning private property for themselves [5].Because for them, the freedom of life, freedom of spiritual actions and devotion to emotions, travels around the world, eco-tourism activities have become more important.

- The growing importance of social media in shaping consumers' perceptions of a product or service. Because it is no secret that nowadays working and communicating on social networks has become an integral part of the lives of all young people.

- Emergence of new types of intellectual property licenses (public licenses) [7]. In this case, the rule of public ownership of the created product or service applies. For example, Creative Common (CC) licenses, which allow people to own intellectual property, are General Public Licenses (GPLs), which provide a collective license for open source software.

- Transformation of business models. The digital economy is reflected in new business models, and this creates a chain reaction that is unique to other market participants. The most popular of these are the pursuit of customized products and services, the desire for personalized services, the inclusion of ecommerce tools in the company's development strategy, and the use of digital business architectures such as Freemium Model, Free to Play, Print on Demand, Full Craudsorsing, Danation [3].
Manufacturing companies can organize direct sales via the Internet, use electronic showcases, create network and inter-network virtual exchanges, drop shopping and meet on-demand stocks.

The development of the digital economy can affect the internal and external environment of international business. There are big changes in the field of information and communication technologies, which can not be reflected in the various areas of activity of companies. They can sell their products all over the world via the internet. Companies with small investments can emerge quickly and grow rapidly. With the help of information technology, there is such an opportunity to reduce costs and at the same time increase labor productivity and efficiency in many sectors of the economy. At the same time, given the digital economy, the position of companies in the market is becoming increasingly complex. The level of risk and uncertainty increases in the strategic decision-making process. This situation will not depend on a stable market situation due to dynamic changes in the technological level, growth of competition and government influence on the economy.Technological changes inherent in the digital economy can create new market rules for producers and buyers. In such an environment, companies need to look for new competitive strategies and increase competitive efficiency. To survive and thrive in a new environment at the same time, companies need to increase their authority in the field of digital information technology.

Not every modern researcher and experienced entrepreneur sees the effectiveness of the digital economy. The threatening aspect to the population is that the most important demonstration of the digital economy is the widespread introduction of robots into manufacturing and services. Recently, even international organizations have realized the dangers that robotization of the economy can cause, as 
robots almost destroy people. It is projected that two-thirds of the third world population will be unemployed in the coming decades. It is no coincidence that the problem belongs to these countries, where material production, which is subject to robotization, predominates.Even at the end of the last century non-cash digital money was formalized. They were issued by central banks and they were called deposit money. Now a new money package will appear which is called personal digital money. According to many experts, this does not make life easier for people. At the same time, the importance of young people in the digital economy, where it is easier for young people to adapt to new technologies, is more important than for adults.

Undoubtedly, the development of the digital economy will affect the employment sector. The following occupations may emerge in the future:

- personal brand manager;

- virtual lawyer;

- moderator of the platform for communication with government officials;

- infostyleist;

- digital linguist;

- term broker;

- interfacedesigner.

It is also necessary to create a national digital economic security system as a result of the development of the digital economy. From the institutional point of view, the concept of "National Digital Economic Security System" is a complex political, legal, organizational, technical, sociocultural system, which consists of a set of objects and entities that provide national digital economic security can be used to protect the level.This means the need to create a regulatory system that regulates public policy, national digital economic security, informal norms and social behavior. The digital economy allows to overcome the limitations inherent in the classical economy due to the presence of some features of the unique function:
1. Few people can use tangible products because digital products don't have such barriers: they can be copied and distributed to an unlimited number of people.

2. Don't use while handling materials. Digital products do not lose their original features, and these features can be improved during collaboration or sharing.

3. Information and communication platforms avoid restrictions on the size of the space available in conventional commercial buildings, as well as the number and quantity of customers served at the same time.

Socio-economic sector growth analysis in the conceptual model of rational creation of the economy taking into account the digitization of the economy Alternative formation of control tasks at different levels from space-time development planning methods leads to the following results:

- The state of the economy is analyzed. This includes studying the economic governance system and its institutional support;

- Levels of farming are determined;

- The subjects of a rational economy are identified;

- The indicators of certain subjects of the rational economy that affect socioeconomic growth are determined;

- Statistical data on indicators are collected;

- Study to identify accuracy and uncertainty, internal and external risks;

- Corrective measures will be taken to ensure the security of a rational economy from internal and external threats of institutional deformations.

There is special software available in our country, in addition to general-purpose software, there is also special software. These include research, design, management of automated production or individual technical means and technological processes, solution of organizational, managerial and economic tasks, management of sales and purchases of goods (works, services), electronic financial calculations, There is access to your organization's database through the 
global information network, including the Internet, electronic legal reference systems, CRM systems, ERP systems, SCM systems, editorial systems, antivirus software, training programs.

The formation of the digital economy must have a certain base, which should be as follows:

- Development of digital infrastructure and communication standards;

- Information security;

- Expansion of On-Line Services;

- creating free access for citizens to intranetwork and On-Line communications;

- Improving information flow and

knowledge management in digital ecosystems.

An important aspect of the formation and implementation of the digital economy is, first of all, the implementation of state regional policy aimed at solving the following problems. It is necessary to increase the investment attractiveness of regions and increase their innovative activity, develop production and social infrastructure, minimize regional disparities in the field of socio-economic development of regions, strengthen interregional relations and rational use of human potential. We propose to define four strategic objectives in the field of regional development: First, to increase the competitiveness of the regions as a socioeconomic system of the regions and strengthen their resource potential; Second, human resource development;Third, the development of interregional cooperation and the creation of institutional conditions for regional development. Fourth, it is necessary to create a system of direct communication and communication to provide software for monitoring financial and economic security at the level of the business entity online in order to effectively manage processes and make the right decisions in a timely manner. These tasks require regular updating, support, monitoring and regular updating at the regional and state levels to respond in a timely manner to targeted government funding of entrepreneurship and small business.Business entities use the Internet to work effectively and continuously at the level of business entities. At the same time, the model of establishing effective cooperation between the subjects of the "business-government" system is integral and important.

In our view, technologies and services for digital systems should include the following:

- Advanced structure of information and communication system;

- Interactive teams participating in objectoriented groups;

- Information resources;

- Database;

- New forms of electronic interactions;

- A platform for the integration of business, government and society;

- Digital environment.

Many developed countries, fully aware of the inevitability of the changes that need to take place, are consciously embarking on a rapid movement towards the digitization of the economy. The United States, Japan, Korea, and China, which were the first to announce this trend, are now unofficial leaders in the digital race. They are followed by the United Kingdom, the European Union, Australia, Belarus and others. Combining these facts, it should be noted that no country, including the leading ones, has a complete philosophical understanding of what the digital economy is and what consequences it may have in the future. It is clear that the digital economy means that many countries do not understand new forms of economic relations and governance, but only new electronic digital forms of consumer communication and payments. Apparently, most countries do not consciously organize the digital economy, but only deal with the process of digitization of existing economic relations. This activity is not considered a targeted process of building a digital economy, despite the obvious degree of obsolescence. Some leading countries in the process of digitization of the economy 
have chosen the opposite approach [3]. For example, the United States has chosen a market direction, while China has chosen a planned economy.

The rest of the countries follow certain intermediate options. It should be noted that, just like China, in terms of the U.S. program, we are seeing a new phase of globalization in the process of digitizing the economy. As the two strongest economies in the world, globalization is beneficial for the U.S. and China because a player who is economically stronger will always have the opportunity to demonstrate their superiority.

\section{Conclusions and Suggestions}

In view of the above, we must pay special attention to the use and application of digital technologies, their availability and quality, different stages of preparation and development increase the level of technical skills in compulsory preschool education and provide higher education and doctoral programs in enterprises and organizations. Such a "social stress test" is necessary for all modern technologies, especially in terms of the management system. Due to the above-mentioned thoughts and ideas, the importance of these social directions for the social environment, in our opinion, may have become much clearer to the reader. But it remains unclear what role their digital economy should play in the Republican program. In the first stage, due to limited resources, it is likely that we will have to decide which direction to focus our efforts, that is, we have two options: one is to socially adapt the technology, and the other is to increase the local technological base.

The formation of a rational economic system at the regional level will form investment in economic and innovative development on the basis of public-private partnership through the identification of sustainable economic growth points, digital formation of areas and directions of development of the region not only in modern conditions, but also priorities. The main factors are the development of media aimed at activating the software, updating the hardware, the development of network technologies the growth of the transaction sector. At the same time, the dissemination of ideas for the development of a competitive economy, trade between consumers, producers, intermediaries in the development of socio-economic and legal relations, described as the information market, forms the market for information products.This approach will strengthen the dominance of the information industry in a number of countries, and the manufacturing and services sectors will become more knowledge-based and innovative.

\section{References}

[1] Gulyamov S.S. and others. Blockchain technologies in the digital economy. Tashkent: IqtisodMolia, 2019. -p. 396.

[2] Ayupov R.X., Baltabaeva G.R. Digital Currency Market: Innovation and Development Prospects. -T: Science and technology, 2018. -p. 172.

[3] Lapidus L.V. Digital economy: management of electronic business and electronic commerce. Moscow: INFRA-M, 2017. -p. 281.

[4] Khodiev B. Yu. Digital economy in Uzbekistan. // World Economy, 2017. No. 12.

[5] Ayupov R.X. and others. Prospects for the development of e-business in Uzbekistan. Tashkent: Polygraph format, $2016 . \quad-$ p. 205. https://ru.wikipedia.org/wiki/Wikipedia page

[6] This definition is provided, in particular, by experts from UNCTAD (The Transformative Economic Impact of Digital Technology, http://unctad.org/meetings/en/Presenta tion/ecn162015p09_Katz_en.pdf)

[7] Alekseev I.V. Information support of the management system of franchising enterprises / I.V. Alekseev, E.V. Riboken // Economics and Humanities. - 2015. - No. 1 (276). - P. 105-110. 
[8] Brian A. Second economy [Electronic resource]. - Access mode: http://www.obs.ru/article/1887/.

[9] Kaluzhsky M.L. Marketing networks in e-commerce: an institutional approach / M.L. Kaluga. - M .; Berlin: Direct-Media, 2014. -402 p.

[10] Mahamadaminovich, S. M. (2020). THE ESSENCE OF SOCIAL CAPITAL CONSEQENCES AND THEIR INFLUENCES TO THE MODERN SOCIETY. Вестник науки и образования, (2-2 (80)).

[11] Kungurov D. Russians are waiting for the digital economy. High technologies are able to revive a weak economy [Electronic resource]. Access mode: https://utro.ru/articles/2016/12/04/130 7336.shtml.

[12] Lutfullaeva, D., \&Kurbanova, M. (2016). Associative Approach to a Language and the Problem of Associative Relation of Words in Uzbek. ANGLISTICUM. Journal of the Association-Institute for English Language and American Studies, 5(7), 61-66.

[13] Petrosyan A. What you need to know about the digital economy and its prospects- [Electronic resource]. Access mode: http://www.kommersant.ru/ doc / 3063024.

[14] Sodirjonov, M. M. (2020). Some Thoughts On The Evolution Of Approaches To The Concept Of Human

Capital. TheAmericanJournalofSocial ScienceandEducationInnovations, $2(0$ 8), 144-150.

[15] Tsvetkov V.A. Implementation of strategies for the new industrialization of the economy / V.A. Tsvetkov, I.M. Stepnov, Yu.A. Kovalchuk // Bulletin of the Financial University. - 2016. - T. 20. - No. 6 (96). - p. 19-30.

[16] Rustamiy, S., Lutfullaeva, D., \&Gulomova, H. (2020). THE IMPORTANCE OF BALAGHA
SCIENCE IN AESTHETIC EDUCATION. PalArch'sJournalofAr chaeologyofEgypt/Egyptology, 17(6), 8882-8886.

[17] Kelly K. New Rules for the New Economy: 10 radical strategies for a connected world / K. Kelly. - New York: Viking, 1998. -p. 224.

[18] Doniyorov, A., Kariev, A., Aminov, H., \&Karimov, N. (2021). The Level of Study of the Religious Image of Mavarounnahr in the IX-XII Centuries. JournalofContemporaryIss uesinBusinessandGovernmentVol, 27 ( $1)$. 